\title{
ERRATUM
}

\section{Erratum to: The Prevalence of HIV, HBV, HCV, and HIV-Related Risk-Taking Behaviors among Palestinian Injecting Drug Users in the East Jerusalem Governorate}

\author{
Aleksandar Štulhofer, Agnes Chetty, Randa Abu Rabie, \\ Isam Jwehan, and Asad Ramlawi
}

\begin{abstract}
The objective of the study was to determine HIV, HBV, HCV seroprevalence and to assess HIV risks among Palestinian injecting drug users (IDUs) in the East Jerusalem Governorate. Following formative research, a bio-behavioral survey using respondent-driven sampling was carried out in 2010 among 199 IDUs aged 19-56 years $(M=41.33, S D=8.09)$. Venous blood was drawn for biological testing. Data on drug abuse and sexual behaviors were collected by face-to-face interviewing. No HIV+cases were found. Five participants were infected with Hepatitis $B$ and 84 participants (estimated population proportion of $40.3 \%$ ) tested positive for Hepatitis C. A great majority of the surveyed IDUs $(90.4 \%)$ reported using sterile injecting equipment the last time they injected. In a multivariate assessment, age (OR=2.52, $p<.05)$, education $(\mathrm{OR}=6.67, p<.01)$, personal network size $(\mathrm{OR}=.18, p<.001)$, and the frequency of drug injecting in the past month $(\mathrm{OR}=.20, p<.001)$ were associated with using sterile injecting equipment in the past week. Condom use at most recent sexual intercourse was reported by about a third (34.2\%) of IDUs. The study documented substantial exposure to HIV risks among Palestinian IDUs whose vulnerability is inseparable from sociopolitic and socioeconomic characteristics of their social environment.
\end{abstract}

KEYWORDS HIV, HBV, HCV seroprevalence, Injecting drug use, HIV risks

The following are the abstract and key words for this article (missing from the article as published):

Stulhofer is with the Faculty of Humanities and Social Sciences, University of Zagreb, Zagreb, Croatia; Chetty is with the WHO Regional Office for Eastern Mediterranean, Cairo, Egypt; Rabie is with the WHO Country Office, Jerusalem, Israel; Jwehan is with the Al-Maqdese Organization, Jerusalem, Israel; Ramlawi is with the Ministry of Health of the Palestinian National Authority, Ramallah, Occupied Palestinian Territory.

Correspondence: Aleksandar Štulhofer, Faculty of Humanities and Social Sciences, University of Zagreb, Zagreb, Croatia. (E-mail: astulhof@ffzg.hr)

The online version of the original article can be found at http://dx.doi.org/10.1007/s11524-012-9672-z. 